\title{
La revista Ínsula y su recepción del cambio poético entre los años 1966 y 1983
}

\section{The Journal Ínsula and its Reception of Poetic Change between 1966 y 1983}

\author{
Jesús María Barrajón Muñoz \\ Universidad de Castilla-La Mancha \\ jesus.barrajón@uclm.es \\ https://orcid.org/0000-0002-2712-1764
}

\begin{abstract}
RESUMEN
El artículo estudia la recepción que la revista Ínsula dispensa a los cambios poéticos que se dieron en España a partir de los años sesenta, sobre todo en los autores que más tarde serían conocidos como novísimos y en aquellos que, más tarde, se distanciaron de la estética de los primeros. La obra de los novísimos es acogida en las páginas de la revista, pero sin el entusiasmo que, a partir de mediados de los setenta, se evidenciará por la poética de los no novísimos, caracterizada por su continuidad respecto a la poesía de la generación del 50. A esos poetas y a los que inician la publicación de sus libros a partir de mediados de los 70 — poesía de la experiencia, neosurrealismo, poética del silencio-, la revista dedicará un mayor espacio y una valoración más positiva.
\end{abstract}

Palabras Clave: Poesía española; novísimos; poesía de la experiencia; transición cultural española; revista Ínsula.

\begin{abstract}
This paper describes how the journal Ínsula received the transformation of Spanish poetry during the $60^{\prime}$ decade of the last century. More specifically, the work focuses on the authors who soon would be known as novisimos and on those who later distanced themselves from the culturalism and the experimentalism of the former ones. The work of the novisimos was actually welcome in the pages of the journal. Nevertheless, it lacked the enthusiasm given in those same years -and, above all, from the mid-seventies on- to the poetics of the non-novisimos, a group characterized by the continuity in relation to the poetry of the 50' decade. If we consider the attitude of its most regular critics, Ínsula dedicated more space and a better opinion to these latter poets and to those who began publishing their books from the mid-70s, the poetry of experience, neosurrealism, the poetics of silence.
\end{abstract}

Key words: Spanish poetry; Spanish poetry of the generation of '68; Poetry of experience; Novísimos; Postnovísimos; Ínsula. 
La revista Ínsula fue durante el periodo de la dictadura franquista y durante buena parte de los años de democracia un referente del mundo literario español, como bien señala Fanny Rubio: «Analizar la trayectoria de Ínsula, la primera publicación de divulgación y crítica literarias verdaderamente independiente de la posguerra, es analizar de paso la historia de la posguerra cultural en nuestro país» (2004: 98). Desde 1946, fecha de su fundación, hasta 1982 fue dirigida por Enrique Canito. Entre 1983 y 1987 la dirigió José Luis Cano, quien hasta ese momento había sido secretario de la revista y verdadera cabeza pensante de la misma. A pesar de su subtítulo, «Revista de ciencias y letras», las secciones sobre ciencia desaparecerían pronto para centrarse de manera fundamental, aunque no únicamente, en la literatura. Años después, sobre todo cuando comenzó a dirigirla Víctor García de la Concha, pasó a ser una revista, como señala Luis Antonio de Villena, «para profesores de literatura» (2011); pero antes de ese momento - en los años, por ejemplo, objeto de nuestro estudio - era una publicación que unía la profundidad de sus artículos con diversas secciones divulgativas, que mezclaba la información literaria con la cinematográfica y la teatral, en la que se ofrecían novedades editoriales y se incluían textos literarios. Es en ese momento en el que la revista consolida su puesto como la más importante del hispanismo y en el que su poder literario es más evidente. Es por esta razón por la que parece especialmente relevante analizar el modo en el que Ínsula recibe en sus páginas uno de los momentos culturalmente más interesantes de la posguerra: el que protagonizan los poetas que de un modo radical rompen en los años sesenta con la poética de las dos primeras generaciones surgidas tras la Guerra Civil. De cómo son acogidas sus propuestas y de cómo, unos años después, lo fueron las de los poetas que les sucedieron quiere tratar este trabajo.

La historiografía sobre el período ha dejado ya establecido que las novedades de los «novísimos» de Castellet (1970) (y de quienes caminan en direcciones similares) no son los únicos síntomas de renovación de la poesía en los sesenta ${ }^{1}$. Aunque ello es así, la radicalidad de sus propuestas sí que resulta especialmente llamativa, por lo que serán ellos los que reciban preferentemente nuestra atención, si bien nos ocuparemos también de aquellos poetas que, nacidos a partir de los últimos años de la década de los treinta, publican sus primeros libros en los años sesenta o en los primeros setenta. La mayor parte de ellos forman parte de la llamada generación del 68 o del 70, dentro de la cual el grupo de los novísimos desempeña durante los años 60 y 70 un principalísimo papel, hasta el punto de convertirse en algunas antologías, como la de

${ }^{1}$ Los cambios literarios y culturales habidos en los sesenta son descritos por Jordi Gracia y Domingo Ródenas (2011: 160-165) con palabras especialmente atinadas que evidencian que esos cambios culturales tuvieron lugar antes que los políticos tras la muerte de Franco. 
Joven poesía española ${ }^{2}$ (1979) de Concepción G. Moral y Rosa M. Pereda, en estética dominante de esa generación. Vendrán después otras, como Las voces y los e $\cos ^{3}$ de José Luis García Martín (1980) y Poetas de los 70 de María Pepa Palomero (1987), que ampliarán la nómina generacional a todos aquellos que no habían roto con las poéticas anteriores (Juan Luis Panero, Antonio Carvajal) o que, coetáneos de los novísimos, publicaron sus primeros libros después de la muerte de Franco ${ }^{4}$ (Francisco Bejarano, Fernando Ortiz, Abelardo Linares). En esos años de transición a la democracia comenzarán a aparecer las primeras obras de los poetas nacidos en los cincuenta, en un abanico de direcciones líricas que enriquece el panorama anterior a la vez que marca un cambio respecto del esquema poético de los novísimos, aunque tampoco podría hablarse de una ruptura, como explica Luis Antonio de Villena en su antología Postnovísimos (1986). Este periodo ha sido estudiado con especial acierto por Araceli Iravedra (2016: 30-68), quien en las páginas introductorias de su antología Hacia la nueva democracia. La nueva poesía (1968-2000) establece el paradigma de la «archiéstetica» novísima (el culturalismo, lo camp, la autonomía de la creación artística, el interés por lo metapoético, la tendencia a la desrealización), pero también su giro poético hacia un "segundo movimiento» (ibíd.: 61-68) de carácter personalizador que en ocasiones coincide con quienes, desde posiciones no novísimas, escriben en esos mismos años y a los que llama «disidentes y ocultos» (ibíd.: 52-61). De esa consolidación novísima y de la progresiva incorporación de quienes no participaban de su estética, dan buena cuenta las páginas de la revista Ínsula.

La elección de las fechas de 1966 y 1983 como inicio y cierre de nuestro estudio, aunque discutible, no es en absoluto caprichosa. Como señala Ángel Luis Prieto de Paula, «entre 1963 y 1966 comenzaron a aparecer algunos libros

2 Sobre esta antología escribe José Luis García Martín: «Cuando en 1979, Concepción G. Moral y Rosa María Pereda publican Joven poesía española, compendio de quince años de estética novísima [con alguna excepción amical], ya la renovación iniciada a mediados de los sesenta se había convertido en un nuevo academicismo, había perdido toda capacidad de sorpresa y, como antes la poesía social, era pasto de epígonos» (1996: 19).

${ }^{3}$ Es una antología en la que conviene reparar de modo especial porque tempranamente ofrece una visión mucho más amplia de la lírica de los años setenta e incorpora a la nómina de la poesía de esos años los nombres de poetas como Fernando Ortiz, Miguel d'Ors, Francisco Bejarano, Eloy Sánchez Rosillo o Víctor Botas, cronológicamente de la generación de los novísimos, pero cuyas primeras obras no aparecen sino hasta los años setenta y en direcciones poéticas diversas de las de los novísimos de la primera hora. En esta antología aparecen también nombres como el de Luis Antonio de Villena, que vira pronto hacia posiciones no novísimas, o José Gutiérrez, que, miembro ya de una generación posterior, se inicia con una voz poética que lo aproxima a Ortiz o Bejarano. Este giro no novísimo será, como se verá a lo largo de estas páginas, muy bien acogido por parte de Ínsula.

${ }^{4}$ Para el estudio de este proceso, véanse José Luna Borge (1992), Juan José Lanz (1994, 1997, 2000 y 2007) y Ángel Luis Prieto de Paula (1996). 
que, si bien no contenían todos los ingredientes que iban a caracterizar el nuevo universo lírico, tampoco podían ya integrarse con comodidad en el que habían construido los autores del medio siglo» (1996: 40)5. Más adelante añade que uun primer momento de consolidación generacional se produce entre 1966 y 1968, con títulos como Arde el mar [1966] de Gimferrer; Dibujo de la muerte [1967] de Carnero; Una educación sentimental [1967] de Vázquez Montalbán; Teatro de operaciones [1967] de Martínez Sarrión; Cepo para nutria [1968] de Félix de Azúa (...)» (Prieto de Paula 1996: 41). El año 1966, de esta manera, con la publicación de un libro emblemático de la nueva estética - Arde el mar - pudiera ser un buen punto de partida para observar el modo en el que una revista como Ínsula recibe este cambio respecto de la poética de los 50. Por su parte, 1983 podría ser considerado como un buen año de cierre, en tanto que es el año de publicación de El jardín extranjero de Luis García Montero, premiado en 1982 con el premio Adonáis, lo que, de alguna manera, supone la consolidación de una estética «post-novísima» que podía ser observada desde 1975 y aún antes. En ese año de 1975 Julia Castillo publica Urgencias sin Nombre y José Lupiáñez, Ladrón de fuego; en 1976, aparece Ofrenda en la memoria de José Gutiérrez, quien en 1978 dará a la luz Espejo y laberinto; en 1977, Último recurso de Antonio Jiménez Millán; en 1979, La lentitud de los bueyes de Julio Llamazares, y Poemas de Salvador López Becerra; en 1980, De una niña de provincias que se vino a vivir en un Chagall; en 1982, Paraíso manuscrito de Felipe Benítez Reyes. Es el momento en el que, igualmente, se dan a conocer los primeros libros de algunos poetas del 68 que no habían publicado antes de la muerte de Franco, como Francisco Bejarano [Transparencia indebida, 1977], Eloy Sánchez Rosillo [Maneras de estar solo, 1978], Abelardo Linares [Mitos, 1979], Fernando Ortiz [Personae, 1981]. Por estos años, a su vez, algunos de los poetas novísimos se encaminan hacia una lírica menos estridente en sus formulaciones culturalistas o exigencias metapoéticas, y coinciden en formas y motivos con algunos de estos otros poetas cuyo primer libro acaba de ser mencionado. Es el caso, por ejemplo, de Luis Antonio de Villena [Huir del invierno, 1981] o Antonio Colinas [Astrolabio, 1979] $]^{6}$. Pasemos a ver cómo la revista Ínsula refleja este recorrido.

${ }^{5}$ Menciona títulos como Mensaje del Tetrarca [1963] de Pedro Gimferrer, Libro de las nuevas herramientas [1964] de José María Álvarez, El silencio [1965] de Agustín Delgado, Amor peninsular [1965] y Un poder humano [1966] de José Miguel Ullán, etc.

${ }^{6}$ Para una mayor información sobre este proceso vivido a partir de 1975, pueden consultarse las antologías de Luis Antonio de Villena (1986 y 1992), José Luis García Martín (1996) y Ángel Luis Prieto de Paula (2010), así como el estudio de Juan José Lanz (2007), especialmente las páginas 47-94. 
LOS AÑOS ANTERIORES A LA MUERTE DE FRANCO: 1966-1975

Durante 1966 y 1967, la poesía de los más jóvenes no tiene un eco excesivo en las páginas de la revista, abierta, sin embargo, como más adelante se verá, a los artículos de esos mismos autores. Un poeta que aparece en 1966 es Félix Grande, de quien Emilio Miró (1966) reseña, destacando su valor testimonial, Música amenazada [1966; Premio Guipúzcoa 1965], y a quien Antonio Núñez (1967) entrevista con motivo de la concesión del Premio Casa de las Américas a su libro Blanco Spirituals [1967]. En 1967, Miró (1967b) también reseñará El silencio [1966] de Agustín Delgado, y Acerca de los viajes [1967] del argentino Marcos Ricardo Barnatán. Se dará igualmente cabida a poemas de Pere Gimferrer (1966a), Juan Luis Panero (1966), Guillermo Carnero (1966) y Antonio Carvajal (1967). En el apartado de «Nuestra selección» (VV. AA. 1967), se incluye Una educación sentimental [1967] de Manuel Vázquez Montalbán, y Dibujo de la muerte [1967] de Guillermo Carnero. De este libro se incluye también una reseña de Emilio Miró (1967a) en la que nos interesa especialmente detenernos porque, aunque la poesía de los autores arriba mencionados suponga, en la mayoría de los casos, un giro sobre la poesía anterior, el que el citado crítico observa en la de Carnero es, en su opinión, más evidente. Miró, un lector de gran sensibilidad, lo sitúa en la dirección de los poetas que pocos años después serían denominados como «novísimos»: «[...] es una aportación a esta reciente vena de poesía literaria, esteticista, de delicada y sutil recreación artística. La influencia de Arde el mar de Gimferrer es indudable, pero sin que esto suponga un fácil y servir mimetismo» (Miró 1967a: 14). Es interesante observar que se menciona el influjo de Gimferrer, a quien la revista encargó en esos años cuatro artículos críticos: «Recuerdo de José Asunción Silva» (1966b), «Situación de Gonzalo Suárez» (1966c); «Memoria de un poeta: Paul-Jean Toulet» (1967a) y «Dos nuevos libros de Octavio Paz» (1967b); y de quien se reseña Arde el mar [1966]. Quien lo hace, curiosamente, no es Miró, sino alguien nada habitual en la crítica de poesía en Ínsula, José-Carlos Mainer (1966), quien lo sitúa en la línea de Cernuda, Guillén y Salinas, al tiempo que destaca su «neo-exotismo», sin, en ningún momento, entrar en valoraciones sobre la dirección poética que Gimferrer representa con ese libro. Otros novísimos realizan sus primeras incursiones en la revista a través de breves estudios o reseñas: José-Miguel Ullán, con dos artículos, «Carlos Fuentes. Salto mortal hacia mañana» (1967a), que aparece en la primera página de la revista, y «El día de la ira (sobre el último libro de José Ángel Valente)» (1967b); y Ana María Moix (1967), con un trabajo sobre el grupo Ditirambo. El artículo de Ullán es especialmente revelador de la postura estética de los poetas que trataban de romper con los esquemas líricos de las generaciones precedentes. Antes de iniciar su crítica de Siete representaciones [1967] de José Ángel Valente, Ullán dibuja un panorama sombrío de la poesía española de ese momento, aunque salva algunos nombres: 
$\mathrm{Y}$ es ruin este forcejeo larvario en que algunos de nuestros poetas y críticos de poesía andan empeñados, manifestando un dogmatismo enfermizo bajo la candorosa máscara de una pureza ética (también frecuentemente estética) a toda vela. En tanto, es curioso, el resto de la poesía occidental se debate con angustiosa lucidez en el marco de sus limitaciones escalofriantes. [.../...] identificar contexto sociopolítico con cultura creativa no pasa de ser una coartada demasiado simple y, además, errónea. [...] A la vista de la salud aquí reinante, uno habrá de pensar que, en efecto, Europa acaba en los Pirineos. ¡Quién sabe! Delimitando, en fin, este preámbulo provisional y urgente, quizá sea necesario entresacar tres nombres que, a mi juicio, salvan la poesía española de los últimos tiempos. No tiene otro sentido esta arriesgada elección más que el de ejemplificar, en cierto modo, a grupas de «los años cincuenta», el reverso de la negatividad que más arriba he acusado. Nombro sin más: Ángel González, Claudio Rodríguez y José Ángel Valente (Ullán 1967b: 7 y 14).

En 1968 y 1969, los dos años previos a la publicación de la antología Nueve novísimos poetas españoles de José María Castellet, la situación es muy parecida a la descrita anteriormente: se reseñan algunos de los libros de los nuevos autores, se incluyen algunos de sus poemas en las secciones dedicadas a creación, se escogen algunas de sus obras para la selección de libros que la revista efectúa mensualmente, y se incluyen algunos — pocos — artículos teóricos escritos por los jóvenes poetas. Emilio Miró es el encargado de presentar algunas de esas obras y de ubicarlas en el panorama poético español. Al ocuparse (Miró 1968b) de Blanco Spirituals de Félix Grande, señala que la renovación de autores como este y Vázquez Montalbán en Una educación sentimental se corresponde, aunque más tardíamente, con la que para la novela significó la aparición de Tiempo de silencio [1962] de Luis Martín Santos. Muy elogiosa es su reseña (Miró 1968a) de La muerte en Beverly Hills [1968] de Pedro Gimferrer, un joven poeta «[...] que irrumpía desde Arde el mar con brillantez, con audacia, no sujeto a direcciones prefijadas, "comprometido" únicamente con la belleza de la palabra poética, con una admirable madurez expresiva, entre un difícil equilibrio entre barroquismo y clasicismo, entre externas libertades e interiores frenos» (Miró 1968a: 6), y que, desde la publicación de Arde el mar, había influido de manera decisiva en los jóvenes poetas. Al final de la reseña, desliza un comentario en el que nos interesa reparar por cuanto nos indica el modo en que cierta crítica recibió la nueva poesía: «Se ha hablado de nueva "torre de marfil", de esteticismo sin salida, de vacía brillantez, de suntuario lujo para pocos» (Miró 1968a: 10). Miró salva a Gimferrer de esa acusación, pero, al tiempo, nos permite ver qué se le achacaba en esos años sesenta. Cuando reseña Cepo para nutria de Félix de Azúa, lo incluye en la línea renovadora de Gimferrer, Carnero y Vázquez Montalbán, y señala su obra, en términos positivos, como «una valiente audacia expresiva, un intento, merecedor de aliento, de rescatar a nuestra palabra poética del realismo y del prosaísmo, del intimismo y del psicologicismo» (Miró 1968c: 6). En otros 
casos, expresa sus reticencias; por ejemplo, en una reseña sobre autores jóvenes como el bonaerense Marcos Ricardo Barnatán, el canario Jorge Rodríguez o el leonés Antonio Colinas, advierte de algunos peligros en el caso del libro de este último, Preludios a una noche total [1969], con relación al cual escribe: «Entre el hipersubjetivismo sentimental y el hermetismo esteticista la joven poesía española puede naufragar» (Miró 1969e: 7). Cuando se interesa por libros de otros jóvenes poetas como Diego Jesús Jiménez [Coro de ánimas, 1968] (Miró 1969a), Antonio Carvajal [Tigres en el jardín, 1968] (Miró 1969b), Alfonso López Gradolí [El sabor del sol, 1968] (Miró 1969c) y Antonio López García [Tierra de nadie, 1968] (Miró 1969d), no los relaciona con los poetas que se mencionaron líneas arriba, sino que, por el contrario, establece su conexión por ejemplo, con Ricardo Molina y Pablo García Baena, en el caso de Carvajal, y con Concha Lagos, Francisco Brines y Juan Luis Panero, en el caso de López Gradolí.

El director de la revista, José Luis Cano, desde su tribuna de «Los libros del mes», se ocupará en contadas ocasiones de los llamados novísimos, y eso sucederá ya bien entrada la década siguiente. Su preferencia por un tipo de poesía más cordial y cercana es evidente, aunque ello no sea obstáculo para que en su labor como director impulse la reseña de sus libros y la colaboración de sus autores ${ }^{7}$. De esa preferencia por un determinado tipo de poesía es muestra su crítica muy favorable (Cano 1968a) de A través del tiempo de Juan Luis Panero, si bien demuestra amplitud de criterios cuando, al reseñar la Antología de la nueva poesía española (Cano 1968b) de José Batlló, en la que están incluidos Gimferrer, Ullán y Vázquez Montalbán, echa en falta el nombre de Panero, pero también el de Carnero.

Los poemas y los libros seleccionados crecen moderadamente respecto a los años anteriores. En 1968 se incluye un poema de José Benito de Lucas (1968), quien había ganado el Premio Adonáis con Materia de olvido; en 1969, uno de Marcos Ricardo Barnatán (1969a) y otro de Jesús Hilario Tundidor (1969). En «Nuestra selección» mensual aparecen libros reseñados como $A$ través del tiempo de Panero (VV. AA. 1968), La muerte en Beverly Hills de Gimferrer (VV. AA. 1968), Coro de ánimas de Jiménez (VV. AA. 1969a), Tigres en el jardín de Carvajal (VV. AA. 1969b), Preludios a una noche total de Colinas (VV. AA. 1969c). Más interesante es la información que puede extraerse de los artículos publicados por los jóvenes poetas. Gimferrer consolida su presencia con cuatro artículos: sobre poesía catalana y Joan Brossa (1968a), sobre Ricardo Molina (1968b), sobre Volverás a Región [1967] de Juan Benet (1969a), y sobre Baltasar Porcel (1969b). Por su parte, Marcos Ricardo Barnatán (1969b) se ocupa de Cortázar y Vicente Molina Foix (1969), de Calvert

\footnotetext{
7 Además de ello, vemos su estima de un autor como Gimferrer en la reseña de la Antología de la poesía modernista de Pere Gimferrer (Cano 1969c).
} 
Casey. La presencia poética de estos autores es limitada en la revista, pero se observa - sobre todo en el caso de Gimferrer - que esta publicación les abre las puertas para tratar teóricamente de escritores y obras que conectan con la renovación literaria que ellos pretendían con su obra poética. Quedan pocos años para que la revista les ceda a algunos de ellos el prestigioso lugar de la primera página.

Si fijamos nuestra atención en los años que van hasta 1975, año en el que muere Franco y en el que, por consiguiente, como toda la vida cultural española, algo se modifica sustancialmente, observamos que paulatinamente la presencia de la joven poesía española se acrecienta, aunque centrada en algunos nombres y sin que pueda decirse que sea mirada con especial simpatía. Emilio Miró continúa siendo el crítico de plantilla, por decirlo así, junto al director, José Luis Cano. El primero acentuará sus críticas al esteticismo durante este período; el segundo ni se ocupará de sus autores. Miró reseña muy elogiosamente Baladas del dulce Jim [1969] de Ana María Moix, aunque señala que «irritará sin duda a muchos y desconcertará a otros» (Miró 1970a: 6). Coincide con lo expresado en la reseña de ese mismo libro revisado - y en el mismo número de la revista - por Marcos Ricardo Barnatán, quien capta muy bien la relación entre la poeta catalana y Carnero, Azúa y Leopoldo María Panero, y señala que «algún lector, más de uno se sentirá algo sorprendido o defraudado al encontrarse con un libro como éste. Debemos recordar que el lector español ${ }^{8}$ no está acostumbrado a "tales atrevimientos" [...]» (Barnatán 1970: 8). Los otros libros que Miró reseña durante esos años son: en el número 280 (Miró 1970b:), Memoria de la muerte [1968] de Antonio López Luna, Oveja negra [1969] de Antonio Hernández, Metamorfosis [1969] de Eugenio Padorno, y Nueva historia de los dioses [1969] de Pedro Rodríguez Pacheco; en el número 283 (Miró 1970c), En voz baja [1969] de Jesús Hilario Tundidor y A flor de piel (1970) de Ángel García López; en el 284-285 (Miró 1970d), Dolor del sur [1969] y Amores con la tierra [1970] de Manuel Ríos Ruiz, Los instantes [1969] de Alfonso López Gradolí, y Las contracifras [1969] de Rafael Ballesteros; en el 294 (Miró 1971a), Los oscuros fuegos [1971] de Justo Jorge Padrón y Vispera de la destrucción [1970] de Jenaro Talens; en el 295 (Miró 1971b), Erosión [1971] de César Simón, Fabulación del tiempo [1971] de Pedro J. de la Peña y Lugar común [1971] y Celda verde [1971] de Pureza Canelo; en el 305 (Miró 1972a), Elegía y no [1972] de José Infante; en el 307 (Miró 1972b), Ritual para un sacrificio [1971] de Jenaro Talens; en el 313 (Miró 1972c), Ítaca [1972] de Francisca Aguirre; en el 316 (Miró 1973a), Transición [1973] de Javier Alfaya; en el 323 (Miró 1973c), Las señales del tiempo [1971] de López Gradolí; en el 326 (Miró 1974a), de Paisono [1972] de Jesús Hilario

${ }^{8}$ Véase que coincide en su apreciación sobre el panorama de la poesía española con Ullán en la cita arriba reproducida de su reseña de Siete representaciones de Valente. 
Tundidor; en el 328 (Miró 1974b), de Coplas la muerte de mi tía Daniela [1973] y A la sombra de las muchachas sin flor [1973] de Vázquez Montalbán. Miró dedica también algunas reseñas a comentar la trayectoria de algunas editoriales de poesía, lo que le permite referirse a poetas que no ha reseñado en la revista; así, informa sobre las colecciones «Poesía-Libros de enlace», de la editorial Barral y de «Inventarios provisionales» (Miró 1970e); sobre «Saco Roto», de la colección «Helios» y «Provincia» (Miró 1973a); sobre las colecciones «El bardo», «Ocnos» y la editorial Visor (Miró 1973b). Muchos de los libros reseñados lo son por haber sido galardonados con algún premio, sobre todo el Adonáis o el Casa de las Américas.

El objetivo de este largo listado, además de su contenido informativo, es el de mostrar que el crítico de poesía de la revista evidencia su deseo de que su espacio en Ínsula esté abierto a diferentes voces, representativas de diversos modos de entender la poesía; pero, al tiempo, deja ver - es evidente la ausencia de varios libros y autores importantes de la poesía más alejada de los patrones de las dos primeras generaciones de posguerra - su escasa simpatía por los llamados «novísimos». En la mencionada reseña de Hontanar de Talens, Miró, nunca agresivo ni descalificador con ningún poeta ni tendencia, deja escapar algún comentario que nos habla de su distancia estética con el grupo en el que incluye a Talens; así, al comienzo de su reseña, leemos: «[...] perteneciente a la última generación de poetas-profesores [...]»; el párrafo final es también, a pesar del elogio aparente, una velada $-\mathrm{o}$ no tanto- crítica:

Pienso que Talens está en el camino. Y también que, dados su rigor y exigencia, no va a ser fácil para él. Pero solo por él nuestra poesía podrá evitar perecer en el juego gratuito, anacrónico, en la miseria y la mentira. Hermoso lenguaje el de Jenaro Talens, conociendo sus trampas, sus límites, reflexionando sobre sus posibilidades, su adecuación a la realidad. Lo más lejos de un esteticismo que nace y muere en su aparente y aparatoso — oquedad e inconsciencia sus soportes - fulgor (Miró 1972b: 6).

Miró, que valora la empresa de Talens y la poesía de otros jóvenes «poetas-profesores», no se siente cercano a esa manera de acercarse al hecho poético porque no comparte su idea de la estética ni el carácter excesivamente intelectual que algunos de ellos imprimen al poema en detrimento de su comunicación afectiva y emocional.

Esta posición de Miró se ve compensada con la apertura de la revista hacia otros críticos que, en secciones menos relevantes que la reservada a aquel, muestran su juicio favorable hacia la obra de autores que Miró no incluye en su sección. Así, por ejemplo, Talens, en su reseña de Génesis de la luz [1969] de Jaime Siles, destaca su carácter primerizo e inmaduro, pero también el hecho de que «revela a un poeta» (Talens 1970: 8). Ya en el año 1971, César Simón (1971) comenta Una perenne aurora [1969] de Jenaro Talens, quien, a su vez, reseña (Talens 1971) la antología Beat generation [1970] de Marcos Ricardo 
Barnatán, quien, por su parte, al escribir sobre la poesía extranjera en España, destaca (1971) el «boom Cavafis» que vive la cultura española. Al año siguiente, Talens (1972b) reseñará muy elogiosamente Edgar en Stéphane [1971] de Azúa, a quien valora como uno de los mejores autores de la poesía joven. Una crítica muy positiva es la firmada por Juan Carlos Curutchet sobre Maniluvios [1972] de Ullán, a quien califica como «uno de los mejores poetas surgidos en España en estos últimos años» (Curutchet 1973: 13). Por su parte, Carnero (1974b) reseña Canon [1973] de Jaime Siles; Ignacio Prat (1974), Serenata y navaja [1973] de Antonio Carvajal; Jaume Pont (1974), Foc cec [1973] de Pere Gimferrer; y Pepe Piera (1974), Ciudad del horizonte [1973] de Pedro J. de la Peña. En 1975, A. C. L., probablemente Antonio Colinas Lobato (1975), reseña muy elogiosamente Tromba mortal para los balleneros [1975] el tercer libro de poemas de Antonio Martínez Sarrión y el primero suyo reseñado en la revista.

Los autores jóvenes que ven publicados algunos de sus poemas son numerosos; sus nombres son: Ángel García López (1970), Antonio Colinas (1970 y 1972b), Antonio Carvajal (1970 y 1972), Justo Jorge Padrón (1970 y 1971), P. A. de la Peña (1970), José Infante (1972), Jesús Hilario Tundidor (1972 y 1974), Félix Pillet (1974), Fernando Ortiz (1975) y Luis Antonio de Villena (1975c). Esta simple enumeración confirma que la revista, a pesar de recibir en sus páginas la poesía de los novísimos siente, una gran simpatía, o incluso predilección, por otras poéticas, como la de aquellos que, por decirlo así, hicieron menos ruido en la renovación de los años 60, o que continuaron, aun con el sello de su juventud y su nueva voz, los tonos de la generación del 50. Varios de los poetas mencionados son los que alguna parte de la crítica ha llamado los olvidados — hasta que son recuperados en la década de los 80 - de la generación del 68 (Carvajal, Infante, Ortiz) o los que, algo mayores que estos, fueron alguna vez incluidos, sin demasiado éxito, bajo el marbete de generación del 60 (López García, Tundidor). Sin embargo, en estos seis años a los que nos estamos acercando los únicos poetas «novísimos», en el sentido castelletiano, que publican sus poemas en las páginas de la revista son Colinas y Villena. Ambos, como también Gimferrer y Carnero, gozaron del reconocimiento de la revista en mayor medida que sus compañeros de generación, como su citación en las páginas anteriores y en las que siguen demuestra. De ellos, solo uno, Antonio Colinas (1971), con dos libros publicados, dispondrá de un espacio para la formulación de lo que es, en buena medida, una poética personal. Sucede muy tempranamente, en 1971, y se le otorga el lugar preferentísimo de la primera página. El título del artículo, «Notas para una poética de nuestro tiempo», puede llamar a engaño y ser confundido con un ensayo general sobre la lírica, pero, en realidad, escondida entre otras consideraciones, se halla una poética personal y, en algún sentido, de grupo. De grupo porque en ella se rechaza, por ejemplo, «el prosaísmo de los últimos años», cuyo verso libre «no era sino prosa cortada caprichosamente» (Colinas 1971: 2), y porque 
los poetas de los que se vale evidencian el cambio de canon poético que los novísimos traían consigo: Poe, Leopardi, Baudelaire, Rimbaud, Valéry, Joyce, Proust, Lorca, Cernuda, Aleixandre, Eliot, Séferis, Cavafis. A la vez, es una poética personal porque en ella late el universo lírico de Colinas, bien distinto del de los poetas con los que apareció vinculado por sus primeros libros: «Se ha de recuperar - nos dice- ese mundo donde se armoniza la realidad y el sueño; ese mundo en que lo divino da dimensión, medida, a todo» (Colinas 1971: 2). En mi opinión, la temprana y cálida acogida que la revista dispensa a Colinas no es sino una muestra más precisamente de la distancia de aquella con esa otra poesía novísima ajena a ese latido romántico que Colinas imprime a su poesía y a su poética.

Encontramos también diversos artículos sobre la obra individual de algunos poetas jóvenes. Jenaro Talens, por ejemplo, escribe un artículo sobre la trayectoria de Gimferrer y sobre lo que significó para su obra la publicación de Els miralls [1970], en la que se vale del idioma catalán, lo que a juicio de Talens «[...] era la única manera no solo de mantener una coherencia interna, sino de mantenerla abriendo nuevos horizontes para una poesía demasiado cerrada ya en sus propios límites» (Talens 1972c: 15). Por su parte, José Antonio Icardo (1975) nos ofrece una visión de conjunto de la poesía de Guillermo Carnero, desde Dibujo de la muerte a Variaciones y figuras sobre un tema de La Bruyère [1974]. Tres años antes había aparecido un artículo sobre Carnero que merece ser destacado especialmente por dos razones; la primera, porque su autor es Francisco Brines (1972), uno de los más destacados poetas de la generación del 50; la segunda, porque en su inicio dibuja una caracterización de la poesía joven especialmente sugerente. El artículo versa sobre el modo en que Carnero integra el título del poema en el texto del mismo, y en cómo ambos forman la unidad del poema. El análisis y la muy favorable opinión de Brines sobre los valores poéticos de Carnero vienen precedidas de las siguientes consideraciones:

[...] quiero resaltar la casi general voluntad en ellos de sorprender al lector: algunos, con voluntad de impresionarle y aun desconcertarle; otros, con la intención lícita de crearle una inédita emoción poética. Para comprobar el prurito apuntado basta leer, en las abundantes antologías que han surgido de todos estos grupos, las poéticas pour épater con que gran parte de los jóvenes autores acompañan su particular selección. Este rasgo caracterizador de un impulso general del grupo será una excelente piedra de toque para conocer la buena poesía cuando ésta surja. Es en los rasgos identificadores de un poeta, o de una escuela poética, donde habrá que buscar el motivo del acierto o del fracaso, teniendo en cuenta que las características que conforman una poesía, nunca son, en sí mismas, buenas o malas (Brines 1972: 4).

Unas líneas antes señalaba que Dibujo de la muerte ratificaba «[...] el cambio estético que en el género poético iniciara un año antes [1966], con Arde el mar, Pedro Gimferrer» (Brines 1972: 4). Tres aspectos pueden ser extraídos 
de estas palabras: la idea de que el cambio estético es el propiciado por el grupo - si así podemos llamarlo- de Gimferrer; que su voluntad principal es la sorprender; que aún está por llegar, aunque ya la hayan hecho visible algunos poetas - Carnero, por ejemplo-, la buena poesía.

Un aspecto importante es el de la presencia de los novísimos y de otros poetas estéticamente cercanos como autores de artículos teóricos, sobre todo a partir del año 1973, si bien se hace notar desde 1970. Es importante que reparemos en este tipo de trabajos por cuanto sus autores son jóvenes escritores a los que la revista da cabida no ya solo para informar de su obra poética, sino también para incidir en la creación de un canon poético diverso del de las generaciones precedentes 9 . Es evidente que la dirección de la revista respeta profundamente el trabajo intelectual de alguno de estos poetas — quizá en mayor medida que su obra lírica- y que están interesados en su opinión; así, por ejemplo, en el año 1970, la revista dedica un monográfico a Bécquer, con motivo del primer centenario de su muerte, y realiza una encuesta (VV. AA. 1970) sobre el poeta sevillano a la que responden poetas como Siles, Barnatán, Colinas, Talens, Carnero, además de otros poetas jóvenes como Benito de Lucas, Carvajal, López Luna, Caro Romero o García López. Años después aparecerán dos páginas dedicadas a realizar una encuesta sobre el surrealismo (VV. AA. 1974), a la que responden poetas tan vinculados, en su mayoría, a la poesía novísima como Molina Foix, López Gradolí, José María Álvarez, José-Miguel Ullán, Villena, Azúa, Carnero, Leopoldo María Panero y Martínez Sarrión. Centrándonos en los artículos teóricos, debemos citar, hasta 1973 incluido, el de Gimferrer (1973) sobre Josep Vicenç Foix; el de Carnero (1970) sobre Manon; los de Prat (1971 y 1973) sobre Jorge Guillén; los de Colinas (1972a) sobre Octavio Paz —en la primera página de la revista - y el primer Aleixandre (1973); y el de Talens (1972a) sobre el Aleixandre surrealista. En 1974 y 1975 estos artículos se hacen más numerosos y privilegian algunos nombres. De este modo, Carnero escribe artículos — ambos en la primera página - sobre Espronceda (1974a) y Aleixandre (1974c); Colinas, que mantiene y acrecienta su presencia, escribe sobre Neruda (1974a) y Octavio Paz (1974b); Luis Antonio de Villena — su poesía apenas si había merecido alguna atención en las páginas de la revista, pero su desembarco como articulista es espectacular con un trabajo en $1974 \mathrm{y}$ tres en 1975 - sobre Luis Cernuda (1974), Brines (1975a), Manuel Mujica Láinez (1975b) y —en la primera página- Antonio de Hoyos y Vinent (1975d). Aunque no es posible decir que su poesía no haya tenido eco en la revista, sí que no es exagerado afirmar, a tenor de lo hasta ahora visto, que la obra lírica de los jóvenes poetas españoles cercanos a la estética novísima es más reducida, o no tan bien recibida como su la labor intelectual.

9 En esa tarea coinciden con un poeta de la generación del 50, José Ángel Valente, cada vez más presente en la revista desde finales de la década de los 60 . 
Queda, finalmente, por consignar, la presencia de algunos artículos importantes sobre nueva poesía «no novísima» como el que José María Montells (1972) dedica a la poesía concreta española, en la que, a juicio del autor, destaca la presencia de Alfonso López Gradolí y, sobre todo, Fernando Millán; y el que el propio López Gradolí (1973), al año siguiente, escribe sobre la poesía experimental del grupo Akzente.

\section{6-1983}

En los años siguientes, desde 1976 hasta 1982, se observa la continuación de la presencia novísima, aunque se hace acompañar de la entrada cada vez más evidente de los olvidados de la llamada generación de 68, así como la temprana incorporación de los jóvenes poetas que comienzan a publicar por esos años en una dirección que se alejaba sustancialmente de la establecida por aquellos novísimos. De lo primero dan cuenta los libros elegidos para formar parte de la selección mensual de la revista, los poemas incluidos y las reseñas de algunas de las obras de estos poetas. Sobre Luis Antonio de Villena, muy activo como articulista de la revista durante los años anteriores, se incluye una reseña de Jaime Siles (1976) sobre Hymnica [1975], en la que, además de una valoración muy positiva de la obra, se señala tempranamente el giro individualizador de los poetas de este grupo, así como una nómina del mismo que evidencia un concepto más amplio que el que habitualmente se tenía en el momento en el que la reseña se escribe:

La más reciente de las promociones poéticas de posguerra — esa que algunos, con ánimo satirizador, llaman veneciana y que otros, omitiendo el castelletiano nombre de novísimos, prefieren denominar generación del lenguaje - describe, en sus últimos libros, un movimiento claro hacia la individualidad. Rasgo que, por otra parte, nunca estuvo ausente en los más representativos de sus miembros. Píénsese, para ello, en la voluntad de estilo que preside la obra de Carnero; en el clímax tan puro de Colinas; en la dislocación tan áspera de Azúa; en la meditación teorética de Talens; en el ceñimiento sugeridor de Mario Hernández o en la ebriedad lingüística de Piera (Siles 1976: 12).

A los dos años de esta reseña de Siles, se va a producir lo que podemos considerar el hecho más claramente consolidador de la estética novísima como poética dominante. El director de la revista, José Luis Cano — en la que es, si no me equivoco, la primera reseña (Cano 1978: 8-9) ${ }^{10}$ que escribe sobre uno

${ }^{10}$ En esta reseña, Cano describe de manera muy positiva El viaje a Bizancio y el conjunto de su obra, aunque, al destacar en la parte final de la misma, el culturalismo villeniano deja escapar un comentario que evidencia su irritación no con el hecho en sí, sino con la posibilidad de que sus autores pudieran considerarlo cosa original: «El culturalismo es 
de los autores de esta generación - dedica su doble página central al comentario del que, hasta ese momento, era el último libro publicado por Villena, El viaje a Bizancio [1978]. Papel incluso más destacado es que el que la revista le concede al año siguiente, cuando su fotografía aparezca en la portada del número de septiembre de 1979, acompañando a un artículo de Francisco Brines sobre su obra y sobre su carácter heterodoxo respecto de la generación a la que pertenece, en lo que no es sino una confirmación de ese mismo giro individualizador del que hablaba Siles. Brines destaca la estrecha relación entre poesía y realidad que se observa en la obra de Villena, esto es «[...] su aparente alejamiento de la [poesía] que hacen muchos de sus compañeros en un punto tan sustancial como es el de la relación existente entre la poesía y la vida» (Brines 1979: 12). En 1981, será José Lupiáñez (1981) quien se encargue de reseñar los relatos incluidos en Para los dioses turcos [1980]. Más tarde, Marcos Ricardo Barnatán (1982) se ocupará del siguiente libro de Villena, Huir del invierno ${ }^{11}$ [1981], del que la revista, en la sección «La flecha en el tiempo» (VV. AA. 1982), ya había anunciado su aparición. Este trato preferente se ve confirmado con la inclusión de un poema suyo (Villena 1977b) y de diversas reseñas y artículos, algunos de ellos en primera página: sobre Floresta española de varia caballería (Villena 1976) de Luis Alberto de Cuenca; sobre el Manuel Machado de El mal poema (Villena 1977a), en lo que supone una temprana revalorización de un poeta que consolidará su presencia en la década siguiente; sobre Carlos Bousoño (Villena 1977c); sobre el poeta José Infante (Villena 1979), en un interesante comentario que nos hace comprobar la apertura de algunos novísimos hacia los no novísimos y, por no haberlo sido, menos conocidos que ellos, aun cuando, como en el caso de José Infante, hubieran merecido el premio Adonáis en 1971 por Elegía y no; y sobre Fernando G. Delgado (Villena 1981).

Antonio Colinas mantiene esa importante presencia de la que ya gozó en años anteriores. Una de sus obras, Astrolabio [1979], resulta ser el segundo poemario de un novísimo del que se ocupa José Luis Cano, lo que puede muy bien ser interpretado como el visto bueno a todo lo que poéticamente Colinas significaba ya para la poesía española. Fijémonos también en que, como en el caso de Villena, Astrolabio confirma ese proceso personalizador del que ya se ha hablado, proceso que, como se ve, era bien recibido por la revista. En los

otro rasgo dominante en Viaje a Bizancio, como lo es en no pocos libros de nuestros jóvenes poetas de hoy. Los novísimos de hace diez años los pusieron de moda, pero naturalmente no era ninguna novedad, porque ya los modernistas, con Rubén a la cabeza, habían cultivado abundantemente la poesía culturalista» (Cano 1978: 9).

${ }^{11}$ En este artículo se enfatiza, como en otros sobre estos poetas, la diferencia entre su poesía y la anterior. Al hablar de sus primeros libros, afirma: «Sus poemas sorprendieron entonces e irritaron a quienes mantenían las orejeras del nacional-realismo» (Barnatán 1982: 3). 
años previos a esta reseña, había sido entrevistado por otro joven colaborador, Fernando G. Delgado (1976), y un poema suyo (Colinas 1979) había sido publicado en uno de los números del año 1979. Tras la reseña de Cano, aparecerá un artículo escrito conjuntamente por dos colaboradores ocasionales de la revista, Esteban Pujals Gesali y Fernando R. de la Flor (1981), y uno del crítico habitual, Emilio Miró (1982g), con motivo de la publicación de la poesía completa de Colinas en la editorial Visor. Miró aprovecha la ocasión para situar su poesía inicial en la línea de la iniciada por Gimferrer con Arde el mar, a la vez que amplía la nómina de los poetas que la integraban con nombres como los de Colinas y Arturo del Villar, excluidos «extrañamente» (Miró 1982: 6) de la antología Nueve novísimos poetas españoles de Castellet.

Otros poetas novísimos que continúan con una presencia destacable en la revista en esos años que van desde 1976 a 1982 son Guillermo Carnero y Jaime Siles, aunque este en menor medida que en años anteriores. El primero sigue desarrollando su tarea crítica en artículos - a veces ubicados en la primera página y centrados sobre poetas alejados de sus planteamientos estéticos - sobre Jaime Gil de Biedma (Carnero 1976a), Juan Luis Panero (Carnero 1976b) y Pere Gimferrer (Carnero 1978), a la vez que es objeto de trabajos en los que su obra es estudiada, como el de César Simón (1976) ${ }^{12}$, el de José Luis Cano (1977) dedicado a reseñar el libro de Carnero sobre el cordobés grupo Cántico, o el de Ignacio Javier López (1980). Al segundo, Siles, lo encontramos fundamentalmente como crítico a través de varias reseñas escritas por él (Siles 1976 y 1981) o sobre su obra (Villa Ribot 1978 y Amorós Moltó 1982). Además de señalar su permanencia en la revista, conviene que reparemos en esa apertura de los novísimos a la poesía de sus coetáneos. Por ejemplo, Carnero (1976b: 10) destaca, respecto de la poesía de J. L. Panero, que su lírica conectaba con la de la generación anterior, aunque perteneciera cronológicamente a la siguiente. En lo que es un cambio de actitud sustancial respecto de los planteamientos iniciales de algunos de los poetas novísimos, Carnero resalta que en el año en el que escribe, 1976, la división entre quienes continuaron el tono de los del 50 y quienes buscaron nuevos lenguajes había sido «corregida en parte» (1976b: 10). Diversos autores y obras de la generación del 50 pre-

${ }^{12}$ Es un artículo interesante para comprobar el divorcio abierto entre algunos de los novísimos y la poesía anterior. En un momento dado, el crítico llega a preguntarse: «Qué puede experimentar un lector formado en los esquemas de A. Machado, Lorca o Hernández, ante El azar objetivo de Guillermo Carnero), por ejemplo». Unas líneas más adelante, añade: «Sería de desear que, al mismo tiempo que se va tirando lastre ideológico y consuetudinario, para alcanzar otras formas de vida, se hiciera también un esfuerzo por acercarse a nuevas estéticas, en un sentido más difícil al que se está acostumbrado, o acostumbrándose» (Simón 1976: 5). No es esta la postura dominante de la revista, a tenor de los gustos del crítico Emilio Miró y del director, pero artículos como éste demuestran la apertura de la misma a corrientes diferentes del pensamiento poético. 
sentaban más riqueza y variedad de la que en un primer momento pudiera pensarse, y, además, en algunas de sus obras de los años 60 se acercaron «al problema de la escritura desde una óptica metalingüística, coincidiendo en ello con una de las más omnipresentes preocupaciones de la generación joven» (Carnero 1976b: 10). Señala, por otra parte, que la acusación que se hacía a esta de despreocuparse de lo humano se venía abajo ante los últimos libros publicados por Gimferrer o él mismo. Como consecuencia de lo anterior, concluye que Panero es un «punto de unión intergeneracional, fecundo y necesario. Dotado a la vez de la necesidad y de la capacidad de expresar la propia experiencia, y de hacerlo desde una atención al lenguaje siempre presente» (Carnero 1976b: 10). Afirmaciones como esta nos ayudan a comprender que la recuperación del 50 y de los poetas que continuaron en parte el tono de aquella generación fue iniciada por los propios novísimos.

Otros novísimos con presencia en la revista durante esos años son Pere Gimferrer y su L'espai desert [1977], reseñado por Sánchez Robayna (1978a); Félix de Azúa y su Poesía 1968-1978 [1979], del que se ocupa José Rojo (1980), y Leopoldo María Panero (1976, 1979, 1980), de quien se publican varios poemas. Muchos de ellos son convocados por la revista para la confección de determinados números monográficos, como el dedicado a la generación del 27 (VV. AA. 1977), en el que participan, entre otros, Villena, Siles y Carnero; o el centrado en la figura de Vicente Aleixandre (VV. AA. 1978), con artículos de Gimferrer, Carnero, Siles, Villena y Colinas. En este tiempo se informa asimismo de la aparición de antologías que los incluyen, entre las que destacan Poesía española contemporánea [1981] de Fanny Rubio y José Luis Falcó, reseñada por Víctor Pozanco (1982), quien se centra más en las ausencias que en la valoración de los poetas que sí la integran; y Florilegium. Poesía última española [1982] de Elena de Jongh, revisada por José Luis Cano, quien destaca el acierto de dar cuenta de dos generaciones poéticas y del paso entre la «generación de 1968» y la más intimista «de 1975» (Cano 1982: 9). En estas antologías ya no solo aparecen, con relación a la última poesía, los novísimos o los que no lo fueron en los años sesenta y comienzos de los setenta, sino que incluso se da cabida a algunos de los poetas que comienzan a publicar con posterioridad a 1975. Son antologías más abiertas a la variedad de la poesía española del momento, en mucha mayor medida, por supuesto, que la de Nueve novísimos de Castellet, o la más tardía, pero poco atenta a esa diversidad, de Joven poesía española [1979] de Concepción G. Moral y Rosa María Pereda.

El paso del tiempo fue permitiendo analizar el panorama lírico con una mayor objetividad. Sin embargo, como tendremos ocasión de comprobar al observar el tratamiento que se les otorga a los no novísimos, pareciera que esa objetividad lo que venía a sancionar era la idea de que, afortunadamente, estos habían abandonado sus «excentricidades» primeras en beneficio de una vuelta al orden poético, en el que ya coincidían, aunque solo en parte, con las otras 
poéticas. Esa parece ser la tónica general no de todos los colaboradores, pero sí del crítico de poesía de la revista y de su director cuando se ocupaba de esos asuntos. Por esta razón resulta destacable la aparición de un artículo de Julia Barella (1981) en el que, ya no centrado en un autor concreto, sino en el grupo, trata de establecer las razones que motivaron la estética novísima: «Una poesía que busca la forma de incorporarse a una realidad cuya percepción le es falseada por la palabra; de incorporarse a esa realidad "ficticia", pues en ella va a residir la posibilidad de encontrar la constante y la seguridad del ser: la identidad» (Barella 1981: 4).

Aunque presentes algunos de ellos en los números de la revista anteriores a 1975, algunos de los poetas de la «generación del 68» no novísimos -ni adscribibles al grupo en su configuración original- consolidan su presencia en las páginas de la revista. Uno de ellos, Andrés Sánchez Robayna, continuará con su labor crítica a la vez que acrecienta su protagonismo poético. De lo primero, con artículos para los que se le reserva la primera página, son muestra sus estudios sobre Juan Ramón Jiménez (Sánchez Robayna 1976a), Octavio Paz y la revista Vuelta (Sánchez Robayna 1977a), y el ya mencionado sobre Gimferrer (Sánchez Robayna 1978); de lo segundo, lo es la inclusión de algunos de sus poemas (Sánchez Robayna 1977b y 1978b), así como la aparición de artículos críticos sobre su obra, como los firmados por Jorge Rodríguez Padrón (1979 y 1981). Juan Luis Panero mantiene, como en años anteriores, una presencia discreta en la revista, con la inclusión del ya mencionado artículo de Carnero (1976b) sobre su segundo libro. La presencia de Antonio Carvajal es algo mayor: dos reseñas de Ignacio Prat (1977 y 1981) sobre su obra, en la segunda de las cuales se plantea la situación de este poeta en las nóminas generacionales, respecto de las cuales señala su «aislamiento» relativo o «independencia» (Prat 1981: 4). Otros poetas cuyo nombre aparece con alguna frecuencia en la revista son Justo Jorge Padrón (Miró 1976 y Artiles 1982), Diego Jesús Jiménez (Miró 1977), Joaquín Benito de Lucas (1977), Álvaro Salvador (1977), César Antonio Molina (1978 y López 1980), Agustín Delgado (Miró 1980a) ${ }^{13}$, Jorge Urrutia (Miró 1980b), Ana María Navales y Francisca Aguirre (Miró 1980c), Arcadio López-Casanova (Romera Castillo 1980), Félix Grande (Carreño y González 1979), Jesús Hilario Tundidor (1979), Fernando G. Delgado (1978) y Villena (1981).

${ }^{13}$ La obra reseñada de Delgado es Antología [1979]; en la crítica de la misma, Miró aprovecha para, como de costumbre, arremeter contra los novísimos: «(...) un poeta merecedor de mejor suerte, que no ha formado parte, como otros buenos, auténticos poetas, de los "novísimos", de la reducida élite que para algunos es la nueva poesía española [y ahí está como muestra la reciente antología Joven poesía española, de Concepción G. Moral y Rosa $\mathrm{M}^{\mathrm{a}}$ Pereda, en donde ni están todos los que son ni son todos los que están» (Miró 1980a: 6). 
Frente a la cierta reticencia que los novísimos parecían despertar en el director de la revista y en Emilio Miró, los no novísimos de la generación del 68 y los jóvenes de la siguiente son inmediatamente reseñados y sus obras mayoritariamente valoradas como un regreso a una poeticidad que nunca debió haberse perdido. De esta manera, entre 1975 y 1982, encontramos la inclusión de poemas de Dionisio Cañas (1976), Álvaro Salvador (1977 y 1980), José Gutiérrez (1978 y 1980), José Lupiáñez (1978 y 1979), Andrés Sánchez Rosillo (1978), José Carlos Cataño (1979, 1980 y 1981) Fernando Ortiz (1980), José Carlos Llop (1980), Julia Castillo (1980) y Amparo Amorós Moltó (1981a y 1981b). La presencia de algunos de estos poetas también se hace destacable como articulistas en la revista. De esta manera, Álvaro Salvador (1978) escribe un artículo sobre la poesía de Antonio Fernández Millán; Fernando Ortiz (1980 y 1981a y 1981b) sobre Pablo García Baena, Manuel Paso y Juan Ramón Jiménez; Miguel d'Ors (1981) sobre Manuel Machado; Amparo Amorós (1981c y 1982) sobre Pere Calders y sobre Jaime Siles ${ }^{14}$; José Lupiáñez (1981) sobre Luis Antonio de Villena; y José Gutiérrez (1982), sobre Narzeo Antino ${ }^{15}$.

La posición de la revista quizá se deje ver con mayor claridad a través de las reseñas y artículos de Emilio Miró. Ya en 1978 critica muy favorablemente Primera despedida [1978] de Fernando Ortiz (Miró 1978), poeta que, como queda dicho en las líneas anteriores, es muy bien recibido en la revista. $\mathrm{Al}$ año siguiente dedica su artículo sobre la colección «Ánade. Libros de poesía» (Miró 1979) de Granada a dibujar la trayectoria poética de José Gutiérrez y José Lupiáñez, dos de los nuevos poetas con los que la revista más simpatiza. Sobre Lupiáñez (Miró 1981a) vuelve en 1981 al destacar la obra de dos poetas de dos generaciones diferentes, Antonio Hernández y el propio Lupiáñez [El jardín de Ópalo, 1980] (Miró 1979), artículo que aprovecha para criticar la estrecha nómina de poetas incluidos en Joven poesía española de Rosa M. Pereda y Concepción G. Moral, así como a destacar los nombres de aquellos que, como Hernández, tendrían que figurar con justicia en la nómina generacional. Ese mismo año reseña obras de Andrés Trapiello [Junto al agua, 1980] y Antonio Abad [Misericor de mí, 1980] (Miró 1981b), Vicente Presa [Teoría de los límites, 1980] y Álvaro Salvador [Las cortezas del fruto, 1980] (Miró 1981d), y

${ }_{14}$ Al año siguiente, Jaime Siles escribirá un texto sobre Amparo Amorós (Siles 1983), lo que nos habla de la comunicación entre algunas de las líneas poéticas seguidas por algunos novísimos y quienes les sucedieron.

${ }_{15} \mathrm{El}$ autor aprovecha el inicio de su artículo para arremeter contra el panorama poético del momento, en lo que, teniendo en cuenta los años en los que se escribe, podría entenderse como una «pulla» a quienes canonizaban la corriente de los novísimos y sus seguidores: «Si la confusión más lamentable preside el panorama de nuestra actual poesía desde la desmesurada proliferación de los llamados "poetas" ("plaga de nuestra época, detestables poetas', dijo ya Catulo), no deberá extrañarnos la casi total falta de atención hacia un reducido número de auténticos creadores que han venido elaborando una obra coherente y valiosa [... ]» (Gutiérrez 1982: 5). 
de Ana Rossetti y de Blanca Andreu (Miró,1981e), con motivo de la concesión, respectivamente, de los premios Gules por Los devaneos de Erato [1979] y Adonáis por De una niña de provincias que se vino a vivir en un Chagall [1980]. También destacará Miró la aparición de una nueva colección de poesía, «Entregas de la ventura» (Miró 1981c), dirigida por Andrés Trapiello y Juan Manuel Bonet. En 1982 se ocupa de Francisco Bejarano [Recinto murado, 1981] (Miró 1982a), de José Fernández Palacios [De un mundo cotidiano, 1981] y José Ramón Ripoll [Sermón de la barbarie, 1981] (Miró 1982b), de Vicente Sabido [Sylva, 1981] y Antonio Enrique [La ciudad de las cúpulas, 1981] (Miró 1982c), de Miguel Galanes [Urgencias sin nombre, 1981] y Salvador García Jiménez [Épica del náufrago, 1981] (Miró 1982d), de Javier Lostalé [Figura en el paseo marítimo, 1981] y Fanny Rubio [Retracciones, 1979] (Miró 1982e), de Acacia Domínguez [Como el viento por la empalizada, 1982] y Miguel Velasco [Las berlinas del sueño, 1981] (Miró 1982f). En todos los casos, son reseñas muy favorables en las que Emilio Miró expresa su gusto por una poesía comunicadora - con independencia de su forma poética- de verdades humanas esenciales, lo que le hace aplaudir obras tan diversas entre sí como las de Andreu y Rossetti, o como las de Trapiello y Lostalé. Esta tendencia del crítico le hace acercarse con especial interés a la llamada «La otra sentimentalidad» en un artículo (Miró 1983) que se sale de nuestro esquema cronológico, pero que creemos muy interesante para dar cuenta de la actitud del crítico y de la revista. Tras reseñar Tristia [1981], el libro firmado por Álvaro Montero (Álvaro Salvador y Luis García Montero), Miró recibe con entusiasmo la publicación de El jardín extranjero [1983], premio Adonáis publicado el mismo año en el que aparece la reseña. Las palabras finales del artículo son elocuentes: «De esta indisoluble ligazón de afectividad e ideología, de intimismo y compromiso, de subjetividad e historia común, nacen los poemas de El jardín extranjero, que nunca ponen en conflicto ideas y sentimientos y persiguen una palabra poética tan libre como hermosa, tan bella como liberadora. Luis García Montero es, en estos momentos, uno de los poetas españoles de mayor interés y en quien podemos depositar esperanzas no ilusorias» (Miró 1983:6).

También es destacable la actitud del director de la revista; frente a su relativo «olvido» de los novísimos, en 1981 encontramos un artículo muy elogioso de José Luis Cano sobre la poesía elegíaca de Fernando Ortiz (Cano 1981). También, al año siguiente, presta atención a Florilegium. Poesía última española (Miró 1982) de Elena de Jongh-Rossell, en la que se incluye la poesía que, valiéndonos del término acuñado por Luis Antonio de Villena, podemos llamar «post-novísima».

En una línea similar a los recién señalados de Miró, cabe consignar otros trabajos; así, José Romera Castillo (1979) dedica un breve texto a Miguel Mas y su libro Celebración de un cuerpo horizontal [1978]; Andrés Soria Olmedo (1979) comenta una antología de poesía andaluza reciente en la se incluyen 
poetas como Fernando Merlo, Justo Navarro, Rafael Álvarez Merlo, Álvaro Salvador, Francisco Gálvez, José Infante, José Luis Amaro, Manuel Lombardo, Antonio Jiménez Millán o Joaquín Lobato; Ignacio Prat (1979) revisa Espejo y laberinto [1978] de José Gutiérrez; Fidel Villar Ribot (1980) se ocupa de Mitos [1979] de Abelardo Linares; José Olivio Jiménez dedica un texto a la obra de Dionisio Cañas, en el que, muy tempranamente — estamos en 1981emplea el término de poesía de la experiencia (Jiménez 1981: 4).

\section{CONSIDERACIONES FINALES}

La revista sigue abierta durante los últimos años estudiados a la poesía y la crítica de los novísimos, que continúan siendo reseñados y colaborando como articulistas. Sin embargo, la actitud positiva hacia una poesía que se aleja de los esquemas de aquellos y retorna a otra poeticidad es significativa. Ello no es óbice para que las voces que se inclinan por una poesía que rehúya todo anquilosamiento sigan siendo oídas. En ese sentido, es destacable la publicación de un artículo de Armando López Castro sobre la crítica española de poesía, en el que acusa a esta de ser «especialmente estrecha, con horizontes muy menguados, que va a buscar sus referencias en lo que tiene debajo de la nariz [...]» (López Castro 1982: 14). Como ejemplo contrario señala la postura poética de José Ángel Valente, de cuyos textos teóricos se vale en su defensa de una labor crítica que, como también la propia poesía, esté alimentada «de muchísimas cosas, de experiencias paralelas que se pueden producir en la pintura, en la novela o en la música» (López Castro 1982: 14).

Durante los dieciocho años de Ínsula que este trabajo revisa, se percibe su carácter plural y una actitud ni estrecha ni de horizontes menguados; pero también, sin duda, se hace evidente una dirección editorial que se siente más cómoda con unas líneas que con otras y que, aunque acepta y acoge la diversidad, apuesta por una poesía como la de los poetas del 50 y la de aquellos que, desde mediados de los setenta y en los ochenta, retoman ese «latido cordial» de poetas como Ángel González, Claudio Rodríguez o Francisco Brines, frente a la mayor «intelectualización» distanciadora de Valente o los novísimos. Sucede esto ya en los años sesenta, cuando los críticos fijos de la revista (sobre todo Emilio Miró y el propio José Luis Cano) mostraban con claridad su incomodidad con las muestras más extremadas de lo novísimo y su simpatía por quienes, a veces con una exigencia de renovación importante, no rompían con una tradición lírica como la de los poetas del 50, o, al menos, no lo hacían con estridencia. En este sentido, es necesario resaltar el relevante papel de la revista en la constitución del canon que hoy parece establecido para la poesía de esos años, el que resulta de la valoración preferente del giro postnovísimo, tan bien acogido en las páginas de la revista, y muy pronto avalado por una antología como Las voces y los ecos de José Luis García Martín. 


\section{BIBLIOGRAFÍA CITADA}

Álvaro, Salvador (1977). «Poemas», Ínsula. 366, mayo, p. 6.

Amorós Moltó, Amparo (1981a). «Poemas», Ínsula. 418, septiembre, p. 2.

Amorós Moltó, Amparo (1981b). «Poemas», Ínsula. 420, noviembre, p. 2.

Amorós Moltó, Amparo (1981c). «Pere Calders, cronista de la verdad oculta», Ínsula. 420, noviembre, p. 3

Amorós Moltó, Amparo (1982). «Diversificaciones: la intensidad de lo extenso», Ínsula. julio-agosto, 428-429, p. 15.

Artiles, Joaquín (1981). «El poeta Justo Jorge Padrón», Ínsula. 422, enero, p. 14.

Barella, Julia (1981). «Poesía en la década de los 70: en torno a los «novísimos»», Ínsula. 410, enero, pp. 4-5.

Barnatán, Marcos Ricardo (1969a). «Poema», Ínsula. 269, abril, p. 3.

Barnatán, Marcos Ricardo (1969b). «El retorno a Cortázar», Ínsula. 271, junio, p. 13.

Barnatán, Marcos Ricardo (1970). «Moix, Ana María. Balada del dulce Jim», Ínsula. 279, febrero, p. 8.

Barnatán, Marcos Ricardo (1971). «Poesía extranjera España. Majes Joyce, Edith Sitwell, Amaru, Matsuo Bashó, Cavafis», Ínsula. 296-297, julio-agosto, p. 27.

Barnatán, Marcos Ricardo (1982). «La belleza hechizada de Luis Antonio de Villena», Ínsula. 430, septiembre, p. 3.

Benito De Lucas, Joaquín (1968). «Poemas», Ínsula. 256, marzo, p. 2.

Benito De Lucas, Joaquín (1977). «Poemas», Ínsula. 366, mayo, p. 6.

Brines, Francisco (1972). «Integración del título en el poema», Ínsula. 310, septiembre, pp. 4 y 7.

Brines, Francisco (1979). «La heterodoxia generacional de Luis Antonio de Villena». Ínsula. 394, septiembre, p. 12.

Cano, José Luis (1968a). «La poesía novísima: Juan Luis Panero», Ínsula. 257. abril. pp. 8-9.

Cano, José Luis (1968b). «Una antología de la nueva poesía española», Ínsula. 260-61, julio-agosto, pp. 17-18.

Cano, José Luis (1969c). «Una antología de la poesía modernista», Ínsula. 277. diciembre. pp. 8-9.

Cano, José Luis (1977). «Guillermo Carnero: El grupo “Cántico" de Córdoba», Ínsula. 364. marzo. pp. 8-9.

Cano, José Luis (1978). «Luis Antonio de Villena: El viaje a Bizancio», Ínsula. 383. octubre. pp. 8-9.

Cano, José Luis (1980). «La poesía de Antonio Colinas: Astrolabio», Ínsula. 399, febrero, pp. 8-9.

Cano, José Luis (1981). «La poesía elegíaca de Fernando Ortiz», Ínsula. 421, diciembre, pp. 8-9.

Cano, José Luis (1982). «Una antología de la poesía española», Ínsula. 430, septiembre, pp. 8-9.

Cañas, Dionisio (1976). «Poemas», Ínsula. 360, noviembre 1976, p. 2.

Carnero, Guillermo (1966). «Poemas», Ínsula. 235. noviembre. p. 2.

Carnero, Guillermo (1970). «Una lanza por Manon», Ínsula. 279. febrero, p. 11.

Carnero, Guillermo (1974a). «El republicanismo de Espronceda», Ínsula. 326, enero, pp. 1 y 16.

Carnero, Guillermo (1974b). «Jaime Siles. Canon», Ínsula. 327, febrero, p. 8. 
Carnero, Guillermo (1974c). «Ámbito como proyecto del surrealismo aleixandrino», Ínsula. 337, diciembre, pp. 1 y 12.

Carnero, Guillermo (1976a). «Jaime Gil de Biedma y la superación del realismo», Ínsula. 351, febrero, pp. 1 у 3.

Carnero, Guillermo (1976b). «Nota de lectura: el segundo libro de Juan Luis Panero (Los trucos de la muerte, 1973)», Ínsula. 355, mayo, p. 10.

Carnero, Guillermo (1978). «La etapa catalana en la poesía de Pedro Gimferrer», Ínsula. 382 , septiembre, pp. 1 y 5.

Carreño, Antonio y González, José (1979). «De Félix Grande a Horacio Martín: la poesía como palimpsesto», Ínsula. 392-393, julio-agosto, p. 3.

Carvajal, Antonio (1967). «Poemas», Ínsula. 246, mayo, p. 2.

Carvajal, Antonio (1970). «Poemas», Ínsula. 282, mayo, p. 2.

Carvajal, Antonio (1972). «Poemas», Ínsula. 306, mayo, p. 2.

Castellet, José María (1970). Nueve novísimos poetas españoles. Barcelona: Barral Editores.

Castillo, Julia (1980). «Poemas», Ínsula. 403, junio. p. 2.

Cataño, José Carlos (1979). «Poemas», Ínsula. 392-93, julio-agosto, p. 17.

Cataño, José Carlos (1980). «Poemas», Ínsula. 409, diciembre, p. 2.

Cataño, José Carlos (1981). «Poemas», Ínsula. 414, mayo, p. 2.

Colinas, Antonio (1970). «Poemas». Ínsula. 279, febrero, p. 16.

Colinas, Antonio (1971). «Notas para una poética de nuestro tiempo», Ínsula. 293, abril, pp. 1-2.

Colinas, Antonio (1972a). «A propósito de una lectura de Octavio Paz», Ínsula. 303, febrero, pp. 1 y 3 .

Colinas, Antonio (1972b). «Poemas», Ínsula. 313, diciembre, p. 3.

Colinas, Antonio (1973). «El primer Aleixandre», Ínsula. 316, marzo, p. 3.

Colinas, Antonio (1974a). «Cosmogonías del Canto general», Ínsula. 330, mayo, p. 3.

Colinas, Antonio (1974b). «¿Ocaso de la vanguardia? Un nuevo libro de Octavio Paz», Ínsula. 337, diciembre, p. 16.

Colinas, Antonio (1975). «Martínez Sarrión, Antonio. Tromba mortal para los balleneros», Ínsula. 342, marzo, p. 6.

Colinas, Antonio (1979). «Poemas», Ínsula. junio, 391 p. 2.

Curutchet, Juan Carlos (1973). «José-Miguel Ullán y las paradojas de la vanguardia», Ínsula. 325, diciembre, p. 13.

Delgado, Fernando G. (1976). «Entrevista a Antonio Colinas: la poesía como revelación», Ínsula. 356-357, julio-agosto, p. 22.

Delgado, Fernando G. (1978). «Poemas», Ínsula. 384, noviembre, p. 2.

García López, Ángel (1970). «Poemas», Ínsula. 278, enero, p. 6.

García Martín, José Luis (1980). Las voces y los ecos. Gijón: Júcar.

García Martín, José Luis (1996). Treinta años de poesía española (1975-1995). Granada: Renacimiento/La Veleta.

Gimferrer, Pere (1966a). «Sonámbulo en primavera», Ínsula. 232, marzo, p. 2.

Gimferrer, Pere (1966b). «Recuerdo de José Asunción Silva», Ínsula. 232, marzo, p. 5.

Gimferrer, Pere (1966c). «Situación de Gonzalo Suárez», Ínsula. 238, septiembre, p. 11.

Gimferrer, Pere (1967a). «Memoria de un poeta: Paul-Jean Toulet», Ínsula. 245, abril, p. 15

Gimferrer, Pere (1967b). «Dos nuevos libros de Octavio Paz», Ínsula. 248-249, julio-agosto, p. 18.

Gimferrer, Pere (1968a). «Poesía catalana. Introducción a Joan Brossa», Ínsula. 254, enero, pp. 4-5.

Gimferrer, Pere (1968b). «En la muerte de Ricardo Molina», Ínsula. 256, marzo, p. 3. 
Gimferrer, Pere (1969a). «En torno a Volverás a Región, de Juan Benet», Ínsula. 266, enero, p. 14.

Gimferrer, Pere (1969b). «El mundo de Baltasar Porcel», Ínsula. 267, febrero, p. 13.

Gimferrer, Pere (1973). «Perfil y ejemplo de J.V. Foix», Ínsula. 317, abril.

Gimferrer, Pere (1978). «Poema», Ínsula. 378, mayo, p. 2.

Gimferrer, Pere (1980). «Poemas», Ínsula. 404-405, julio-agosto, p. 7.

Gracia, Jordi y Domingo Ródenas (2011). Historia de la literatura española 7. Derrota y restitución de la modernidad 1939-2010. Barcelona: Crítica.

Gutiérrez, José (1982). «El exilio y el reino de Narzeo Antino», Ínsula. 426, mayo, p. 5.

Icardo, José Antonio (1975). «Guillermo Carnero, del trobar ric al trobar clus», Ínsula. 341, abril, p. 3.

Infante, José (1972). «Poemas», Ínsula. 304, marzo, p. 10.

Iravedra, Araceli (2016). Hacia la democracia. La nueva poesía (1968-2000). Madrid: Visor.

Jiménez, José Olivio (1981). «Las señas de identidad de un nuevo poeta (Dionisio Cañas)», Ínsula. 419, octubre, p. 4.

Lanz, Juan José (1994). La llama en el laberinto. Poesía y poética de la generación del 68. Mérida: Editora Regional de Extremadura.

Lanz, Juan José (ed.) (1997). Antología de la poesía española (1960-1975). Madrid: Espasa.

Lanz, Juan José (2000). Introducción al estudio de la generación poética española de 1968. (Elementos para la elaboración de un marco histórico-crítico en el período 1962-1977). Bilbao: Editorial de la Universidad del País Vasco / Euskal Herriko Unibersitatea.

Lanz, Juan José (2007). La poesía española durante la Transición y la generación de la democracia (1973-2000), Madrid: Devenir.

López, Julio (1980). «Técnica y lenguaje de la poesía épica (A propósito de Últimas tardes en Lisca Blanca)», Ínsula. 407, octubre, pp. 14-15.

López, Ignacio-Javier (1980). «Ironía, distancia y evolución en Guillermo Carnero», Ínsula. 408, noviembre, pp. 1 y 10.

López Castro, Armando (1982). «La crítica española sobre poesía», Ínsula. 424, marzo, p. 14.

López Gradolí, Alfonso (1973). «Akzente, poesía experimental española en Alemania», Ínsula. 314-315, enero-febrero, p. 28.

Luna Borge, José (1992). La generación poética del 70. Cuestión de perspectiva. Sevilla: Qüásydeitorial.

Lupiáñez, José (1978). «Poemas», Ínsula. 378, mayo, p. 2.

Lupiáñez, José (1979). «Poemas», Ínsula. 394, septiembre, p. 2.

Lupiáñez, José (1981). «Para los dioses turcos, de Luis Antonio de Villena. La belleza que tange la muerte», Ínsula. 418, septiembre, p. 10.

Llop, José Carlos (1980). «Poemas», Ínsula. 402, mayo, p. 2.

Mainer, José-Carlos (1966). «Gimferrer, Pedro: Arde el mar», Ínsula. 233. abril. p. 9.

Miró, Emilio (1966). «Crónica de poesía. Ridruejo, Gloria Fuertes, F. Grandes», Ínsula. 235. junio. p. 5.

Miró, Emilio (1967a). «Crónica de poesía: Gastón Baquero. José Batlló. Guillermo Carnero», Ínsula. 248-49. julio-agosto. p. 14.

Miró, Emilio (1967b). «La poesía. Luis Rosales. Concha de Marco. Agustín Delgado. Marcos Ricardo Barnatán», Ínsula. 253, diciembre, p. 6.

Miró, Emilio (1968a). «Pedro Gimferrer: La muerte en Beverly Hills», Ínsula. 258, mayo, pp. 6 y 10.

Miró, Emilio (1968b). «Crónica de poesía: Pilar Paz. Molina Campos. F. Grande», Ínsula. 255, junio, p. 6. 
Miró, Emilio (1968c). «Crónica de poesía: Julia Uceda. J. Benito de Lucas. J.L. Cano. José María Velázquez. Félix de Azúa», Ínsula. 264, noviembre, p. 6.

Miró, Emilio (1969a). «Crónica de poesía: E. De Champourcin. I.M. Gil. J. Casalduero. Diego Jesús Jiménez», Ínsula. 267, febrero, pp. 6 y 15.

Miró, Emilio (1969b). «Crónica de poesía: Francisco Salgueiro. Antonio Carvajal. Ángel González. Manuel Álvarez Ortega», Ínsula. 270, mayo, p. 6.

Miró, Emilio (1969c). «José Ramón Medina. Fernando Quiñones. Alfonso López Gradolí. Enrique Badosa», Ínsula. 272-273, julio-agosto, p. 37.

Miró, Emilio (1969d). «Crónica de poesía. Tres poetas», Ínsula. 274, septiembre, p. 6.

Miró, Emilio (1969e). «Cinco poetas jóvenes. Joaquín Caro Romero. Marcos Ricardo Barnatán. Antonio Colinas. José Caballero Millares. Jorge Rodríguez Padrón», Ínsula. 277, diciembre, pp. 6-7.

Miró, Emilio (1970a). «Crónica de poesía. Seis mujeres», Ínsula. 279, febrero, pp. 6-7.

Miró, Emilio (1970b). «Crónica de poesía. Cuatro poetas jóvenes», Ínsula. 280, marzo, pp. 6-7.

Miró, Emilio (1970c). «Crónica de poesía. La continuidad de cuatro poetas», Ínsula. 283, junio, p. 6.

Miró, Emilio (1970d). «Crónica de poesía. Cuatro poetas jóvenes», Ínsula. 284-285, julio-agosto, p. 28.

Miró, Emilio (1970e). «Poesía. Una antología y dos nuevas colecciones», Ínsula. 288, noviembre, p. 7.

Miró, Emilio (1971a). «Poesía. Dos jóvenes poetas», Ínsula. 294, mayo, p. 6.

Miró, Emilio (1971b). «Crónica de poesía. César Simón, Pedro J. de la Peña, Pureza Canelo», Ínsula. 295, junio, p. 10.

Miró, Emilio (1972a). «Poesía. Blas de Otero. Enrique Badosa. José Infante», Ínsula. 305, abril, pp. 6-7.

Miró, Emilio (1972b). «Poesía. Joaquín Marco, Jenaro Talens, Jacinto-Luis Guereña», Ínsula. 307, junio, p. 6.

Miró, Emilio (1972c). «Poesía. Gerardo Diego. Francisca Aguirre», Ínsula. 313, diciembre, p. 6.

Miró, Emilio (1973a). «Poesía. Dos colecciones y tres poetas», Ínsula. 316, marzo, pp. 5-6.

Miró, Emilio (1973b). «Poesía. Tres colecciones», Ínsula. 319, junio, p. 6.

Miró, Emilio (1973c). «Poesía. Alfonso López Gradolí y Ramón Pedrós», Ínsula. 323, octubre, p. 6.

Miró, Emilio (1974a). «Poesía. Ernestina de Champourcín. Jesús Hilario Tundidor», Ínsula. 326, enero, p. 6.

Miró, Emilio (1974b). «Poesía. Testimonio y sarcasmo en dos poetas», Ínsula. 328, marzo, p. 6.

Miró, Emilio (1976). «Poesía. Dos poetas canarios», Ínsula. 356-357, julio-agosto, p. 21.

Miró, Emilio (1977). «Diego Jesús Jiménez y la colección Alfar», Ínsula. 366, mayo, p. 6.

Miró, Emilio (1978). «Poetas andaluces», Ínsula. 383, octubre, p. 6.

Miró, Emilio (1979). «Una nueva colección: “Ánade”», Ínsula. 388, marzo, p. 6.

Miró, Emilio (1980a). "Antologías de Cristina Lacasa y Agustín Delgado», Ínsula. 398, enero, p. 6.

Miró, Emilio (1980b). «Dos generaciones: Leopoldo de Luis y Jorge Urrutia», Ínsula. 399, febrero, p. 2

Miró, Emilio (1980c). «Francisca Aguirre y Ana María Navales», Ínsula. 404-405, julio-agosto, pp. 12-13.

Miró, Emilio (1981a). «Dos promociones: Antonio Hernández y José Lupiáñez», Ínsula. 410 , enero, p. 6. 
Miró, Emilio (1981b). «Poesía joven: Andrés Trapiello y Antonio Abad», Ínsula. 411, febrero, p. 6.

Miró, Emilio (1981c). «Fernando Quiñones y una nueva colección: "Entregas de la ventura"», en Ínsula. 414, mayo, p. 6

Miró, Emilio (1981d). «Dos poetas de los setenta: Vicente Presa y Álvaro Salvador», Ínsula. 415 , junio, p. 6

Miró, Emilio (1981e). «Dos poemarios para dos nuevas voces: Blanca Andreu y Ana Rossetti», Ínsula. 418, septiembre, p. 6.

Miró, Emilio (1982a). «Recinto murado: segundo libro de Francisco Bejarano», Ínsula. 422, enero, p. 6.

Miró, Emilio (1982b). «Dos poetas gaditanos: Jesús Fernández Palacios y José Ramón Ripoll», Ínsula. 424 , marzo, p. 6.

Miró, Emilio (1982c). «Nuevos poetas: Vicente Sabido y Antonio Enrique», Ínsula, 425, abril, p. 6.

Miró, Emilio (1982d). «Dos nuevos poetas: Miguel Galanes y Salvador García Jiménez», Ínsula. 427, junio, p. 6.

Miró, Emilio (1982e). «Dos jóvenes poetas entre Cernuda y la metáfora», Ínsula. 430, septiembre, p. 6.

Miró, Emilio (1982f). «Dos jóvenes poetas: Acacia Domínguez y Miguel Velasco», Ínsula. 432, noviembre, p. 6.

Miró, Emilio (1982g). «La poesía reunida de Antonio Colinas», Ínsula. 433, diciembre, pp. 6-7.

Miró, Emilio (1983), «Dos poetas de Granada y "la otra sentimentalidad”», Ínsula. 443, octubre, p. 6.

Moix, Ana María (1967). «Ditirambo aún vela por nosotros», Ínsula. 252, noviembre, p. 14.

Molina, César Antonio (1978). «Poemas», Ínsula. 383 octubre, p. 2.

Molina Foix, Vicente (1969). «En la muerte de Calvert Casey», Ínsula. 272-273, julio-agosto, p. 40.

Montells, José María (1972). «Poesía concreta española», Ínsula. 304, marzo, p.7.

Moral, Concepción G. y Rosa M. Pereda (1979). Joven poesía española. Cátedra: Madrid.

Núñez, Antonio (1967). «Encuentro con Felix Grande», Ínsula. 245, mayo, p. 4.

Ors, Miguel d' (1981). «Manuel Machado ante el teatro del 27 (A propósito de unos textos olvidados)», Ínsula. 413, abril, pp. 1 y 12).

Ortiz, Fernando (1975). «Poemas», Ínsula. 339, febrero, p. 2.

Ortiz, Fernando (1980). «Poemas», Ínsula. 400-401, marzo-abril, p. 25.

Ortiz, Fernando (1980). «Pablo García Baena: el don de la elegía», Ínsula. 404-405, julio-agosto, p. 14.

Ortiz, Fernando (1981). «Manuel Paso: crítica del colonialismo español en la obra de un poeta granadino», Ínsula. 413, abril, p. 4.

Ortiz, Fernando (1981). «Juan Ramón, crítico literario», Ínsula. 416-17, julio-agosto, p. 23.

Padrón, Jorge Justo (1970). «Poemas», Ínsula, 284-285, julio-agosto, p. 14.

Padrón, Jorge Justo (1971). «Poemas», Ínsula. 292, marzo, p. 2.

Panero, Juan Luis (1966). «Poemas», Ínsula. 235, junio, p. 2.

Panero, Leopoldo María (1976). «Poemas», Ínsula. 361, diciembre, p. 2.

Panero, Leopoldo María (1979). «Poemas», Ínsula. 388, marzo, p. 2.

Panero, Leopoldo María (1980). «Poemas», Ínsula. 406, septiembre, p. 2.

Palomero, Mari Pepa (1987). Poetas del 70. Madrid: Hiperión.

Peña, Pedro J. de la (1970). «Poemas», Ínsula. 287, octubre, p. 2. 
Piera, Pepe (1974). «De la Peña, Pedro J. Ciudad del horizonte», Ínsula. 336, noviembre, p. 8.

Pillet, Félix (1974). «Poemas», Ínsula. 335, octubre, p. 2.

Pont, Jaume (1974). «Foc cec, de Pere Gimferrer. Seis poetas catalanes de hoy», Ínsula. 336, noviembre, p. 4.

Pozanco, Víctor (1982). «Rubio, Fanny, y Falcó, José Luis: Poesía española contemporánea», Ínsula. 423, febrero, p. 8.

Prat, Ignacio (1971). «Una edición crítica del Cántico de 1936», Ínsula. 294, mayo, p. 13.

Prat, Ignacio (1973). «Jorge Guillén», Ínsula. 324, noviembre, p. 3.

Prat, Ignacio (1974). «Carvajal, Antonio. Serenata y navaja», Ínsula. 335, octubre, p. 8.

Prat, Ignacio (1977). «Nota de lectura (Casi una fantasía, de Antonio Carvajal)», Ínsula. 373, diciembre, p. 4.

Prat, Ignacio (1979). «José Gutiérrez. Espejo y laberinto», Ínsula. 394, septiembre, p. 8.

Prat, Ignacio (1981). «Sobre Siesta en el mirador de Antonio Carvajal», Ínsula. 410, enero, p. 4.

Prieto De Paula, Ángel Luis (1996). Musa del 68. Claves de una generación poética. Madrid: Hiperión.

Prieto De Paula, Ángel Luis (2010). Las moradas del verbo. Poetas españoles de la democracia. Antología. Madrid: Calambur.

Pujals Gesali, Esteban y Rodríguez de la Flor, Fernando (1981). «Un aspecto de la poesía de Antonio Colinas», Ínsula. 410, enero, p. 3.

Rodríguez Padrón, Jorge (1979). «Andrés Sánchez Robayna: la palabra insular», Ínsula. 392-393, julio-agosto, pp. 1 y 24.

Rodríguez Padrón, Jorge (1981). «Andrés Sánchez Robayna: la escritura como experiencia», Ínsula. 421, diciembre, p. 3.

Rojo, José (1980). «Félix de Azúa: Poesía 1968-1978», Ínsula. 406, septiembre, p. 11.

Romera Castillo, José (1979). «Miguel Mas. Celebración de un cuerpo horizontal. Libros Dante, Madrid, 1978», Ínsula. 391, junio, p. 8.

Romera Castillo, José (1980). «La poesía de Arcadio López-Casanova», Ínsula. 404-405, julio-agosto, p. 23.

Rubio, Fanny (2004). Las revistas poéticas españolas 1939-1975 (1976). Alicante: Universidad.

Salvador, Álvaro (1977). «Poemas», Ínsula. 378, mayo, p. 2.

Salvador, Álvaro (1978). «El último recurso: la pasión por la poesía», Ínsula. 380-81, julio-agosto, p. 16.

Salvador, Álvaro (1980). «Poemas», Ínsula. 404-405, julio-agosto 1980, p. 7.

Sánchez Robayna, Andrés (1976a). «Juan Ramón Jiménez y En el otro costado», Ínsula. 350, enero, pp. 1 y 12.

Sánchez Robayna, Andrés (1977a). «Octavio Paz y Vuelta», Ínsula. 364, marzo, pp. 1 y 12.

Sánchez Robayna, Andrés (1977b). «Poemas», Ínsula. 362, enero, p. 2.

Sánchez Robayna, Andrés (1978a). «El espacio del poema», Ínsula. 376, marzo, pp. 1 y 12.

Sánchez Robayna, Andrés (1978b). «Poemas», Ínsula. 377, abril, p. 2.

Sánchez Rosillo, Andrés (1978). «Poemas», Ínsula. 382, septiembre, p. 2.

Siles, Jaime (1976). «Sobre la poesía última de Luis Antonio de Villena», Ínsula. 350, enero, p. 12.

Siles, Jaime (1981). «La poesía de Luis Suñén», Ínsula. 420, noviembre, p. 12.

Siles, Jaime (1983). «La poesía como conceptualización: Ludia de Amparo Amorós», Ínsula. 443, octubre, p. 19.

Simón, César (1971). «Talens, Jenaro, Una perenne aurora», Ínsula. 293, abril, p. 8. 
Simón, César (1976). «Un problema de astimito: la poesía de Guillermo Carnero», Ínsula. 361 , diciembre, p. 5.

Soria Olmedo, Andrés (1979). «Una nueva antología de poetas andaluces», Ínsula. 392-93, julio-agosto, p, 25.

Talens, Jenaro (1970). «Siles, Jaime. Génesis de la luz», Ínsula. 289, marzo, p. 8

Talens, Jenaro (1971). «Barnatán, Marcos Ricardo. Antología de la "Beat generation"», Ínsula. 295, junio, p. 8.

Talens, Jenaro (1972a). «Vicente Aleixandre y el surrealismo», Ínsula. 304, marzo, p. 3.

Talens, Jenaro (1972b). «Edgard en Stéphane, de Féix de Azúa», Ínsula. 304, marzo, p. 7.

Talens, Jenaro (1972c). «Reflexiones en torno a la poesía última de Pere Gimferrer», Ínsula. 304, marzo, p. 15.

Tundidor, Jesús Hilario (1969). «Poemas», Ínsula. 275-276, octubre-noviembre, p. 2.

Tundidor, Jesús Hilario (1972). «Poemas», Ínsula. 311, octubre, p. 2.

Tundidor, Jesús Hilario (1974). «Poemas», Ínsula, 331, mayo, p. 3.

Tundidor, Jesús Hilario (1979). «Poemas», Ínsula. 395, octubre, p. 2.

Ullán, José Miguel (1967a). «Carlos Fuentes. Salto mortal hacia mañana», Ínsula. 245, abril, 4, pp. 1 y 12.

Ullán, José Miguel (1967b). «El día de la ira (Sobre el último libro de José Ángel Valente», Ínsula. 252, noviembre, pp. 7 y 14.

Villar Ribot, Fidel (1978). «Siles, Jaime. Alegoría», Ínsula. 379, junio, p. 8.

Villar Ribot, Fidel (1980). «Linares, Abelardo: Mitos», Ínsula. 402, mayo, p. 8.

Villena, Luis Antonio de (1974). «Luis Cernuda y el fuego superrealista», Ínsula. 337, diciembre, p. 4

Villena, Luis Antonio de (1975a). «De luz, de tiempo, de palabra, de hombres. Sobre la poesía de Francisco Brines», Ínsula. 338, enero, pp. 4-5.

Villena, Luis Antonio de (1975b). «Inicio de exploración del país: Mújica Lainez», Ínsula. 340, marzo. p. 3.

Villena, Luis Antonio de (1975c). «Poemas», Ínsula. 346, septiembre, p. 2.

Villena, Luis Antonio de (1975d). «Antonio de Hoyos y Vinent y su novela decadente», Ínsula. 348 , noviembre, p. 1.

Villena, Luis Antonio de (1976). «El sueño de la caballería», Ínsula. 359, octubre, p. 10.

Villena, Luis Antonio de (1977a). «Relectura de El mal poema de Manuel Machado (Notas sobre "modernismo y bohemia"», Ínsula. 362, enero, pp. 1 y 11.

Villena, Luis Antonio de (1977b). «Poemas», Ínsula. 370, septiembre, p. 2.

Villena, Luis Antonio de (1977c). «Poesía y autorreflexión de Carlos Bousoño», Ínsula. 373, diciembre, pp. 1 y 11.

Villena, Luis Antonio de (1979). «La nieve desolada de José Infante», Ínsula. 390, mayo, p. 12.

Villena, Luis Antonio de (1981). «Fernando G. Delgado y su opción metafísica», Ínsula. 418, septiembre, p. 12.

Villena, Luis Antonio de (ed.) (1986). Postnovísimos. Madrid: Visor.

Villena, Luis Antonio de (ed.) (1992). Fin de siglo. El sesgo clásico en la última poesía española. Madrid: Visor

Villena, Luis Antonio de (2011). «Memoria de José Luis Cano», El mundo. 18 de mayo. Accesible en: <http://luisantoniodevillena.es/web/articulos/memoria-de-jose-luis-cano/> 27 de agosto de 2013.

VV. AA. (1967). «Nuestra selección», Ínsula. 245, abril, p. 11.

VV. AA. (1968). «Nuestra selección», Ínsula. 256, marzo, p. 11.

VV. AA. (1969a). «Nuestra selección», Ínsula. 266, enero, p. 10. 
VV. AA. (1969b). «Nuestra selección», Ínsula. 268, febrero, p. 13.

VV. AA. (1969c). «Nuestra selección», Ínsula. 271, junio, p. 14.

VV. AA. (1970). «Bécquer, hoy. Encuesta a la joven poesía», Ínsula. 289, diciembre, pp. 4-5.

VV. AA. (1974). «Encuesta surrealismo», Ínsula. 337, diciembre, pp. 8-9.

VV. AA. (1977). Número monográfico dedicado a la Generación del 27, Ínsula. 368-369. julio-agosto.

VV. AA. (1978). Número monográfico dedicado a Vicente Aleixandre, Ínsula. 374-375, enero-febrero.

VV. AA. (1982). «La flecha en el tiempo», Ínsula. 425, abril, p. 2.

Fecha de recepción: 17 de octubre de 2016.

Fecha de aceptación: 29 de marzo de 2017. 